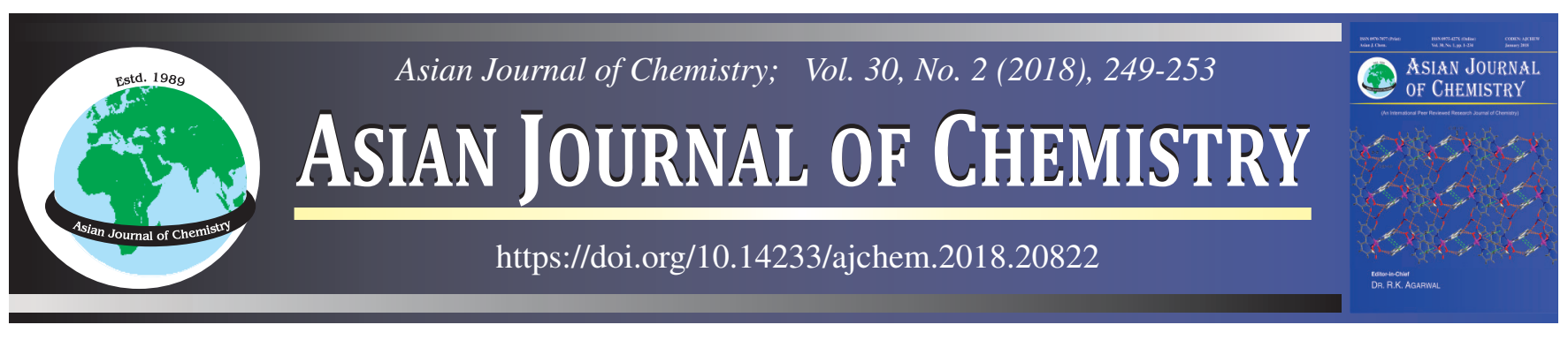

\title{
Solar Assisted Adsorptive Removal of Sulphonic Acid Dyes from Synthetic Wastewater Using Metal Salt Doped Polyaniline Composite
}

\author{
T. Vimala*, M. Karthika and D. AnUSha
}

PG and Research Department of Chemistry, Seethalakshmi Ramaswamy College, Trichirappalli-620 002, India

*Corresponding author: E-mail: vimalsrc@gmail.com

\begin{abstract}
In this paper, metal salt doped with PANI (polyaniline composite) used as an adsorbent for the removal of azo dyes from aqueous solution assisted by solar light. The effectiveness of this process has been investigated by varying parameters such as contact time, initial concentration of dye solution, adsorbent dosage, temperature, electrical conductivity and $\mathrm{pH}$. This experiment was carried out by irradiating the aqueous solution of dye containing adsorbent in solar light. Kinetic data well fitted for pseudo-second order model. Dyes loaded PANI composite was characterized by SEM technique. The adsorbent was found to be effective and economically attractive.

Keywords: Polyaniline, Dye, Solar light, Adsorption capacity.
\end{abstract}

\section{INTRODUCTION}

In recent decades, the effects of water pollution have strongly alters the balance of nature, which ultimately impacts all humans. The lack of suitable water available for drinking, agriculture, farming etc. has declined through the years. This makes waste water treatment and waste water reduction become important issues [1]. Due to extensive usage of dyes in many industrial fields such as textile industry, paper production, leather tanning industry, food technology, photo electrochemical cells and hair colourings [2]. Over 70,000 tons of different types of dyes and pigments are produced annually, out of which about 20-30 \% dyes are wasted as industrial effluents during finishing processes [3]. Many of these dyes are toxic, nonbiodegradable and potentially carcinogenic [4-6].

Among the textile dyes azoic dyes which contribute to about $70 \%$ of all used dyes [7]. Azo dyes are difficult to degrade because of their stability to light and oxidizing agents and also they are resistant to aerobic digestion. In azo dyes, the destruction of chromophoric group is important for the removal of colour and the sulphonic acid groups present in the structure play the role of weak auxochrome which increase the solubility of dye in water. Conventional biological treatments are also used to treat the wastewater but due to hazardous effects of reactive dyes on microbial population, the efficiencies of these processes are reduced [8]. Therefore, methods for decolorization of textile wastewater have received considerable attention in recent years. Developments of advanced oxidation processes led to further improvements in the oxidative destruction of

dyes. These processes generally involve systems such as photofenton, semi conductor/UV, $\mathrm{UV} / \mathrm{H}_{2} \mathrm{O}_{2}, \mathrm{UV} / \mathrm{O}_{3}$ and potential use of solar radiation [9] for the oxidative degradation of contaminants, which gives encouraging results for the removal of azo dye from wastewater [10]. Heterogeneous photocatalysis using metal oxide doped with PANI employed by several workers as adsorbent [11-14]. The main objective of this work was to study the photocatalytic decolourization of sulphonated azo dyes by $8 \%$ PANI-CuCl${ }_{2}$ catalyzed by solar light.

\begin{tabular}{l}
\hline EXPERIMENTAL \\
\hline In the experimental studies, CHEMILINE-micro controller \\
based spectrophotometer CL-330 model was used for \\
determination of dye concentrations. Equip-Tronics digital pH \\
meter model EQ-610 was used in pH measurements for adsorp- \\
tion experiments. Pellet maker-Techno search instrument was \\
used to make the PANI-CuCl ${ }_{2}$ pellets (before and after adsorp- \\
tion) and Four Probe Set-up model: DFP-03 used in the conduc- \\
tometric measurements was obtained from scientific equipment \\
$\&$ services, Roorkee. \\
Naphthol blue black B (NBBB) used in the adsorption \\
studies was obtained from Glaxo India Ltd., Mumbai. Metanil \\
yellow (MY), acid blue 9 (AB 9) and amaranth (AM) were \\
procured from Loba Chemie Pvt. Ltd., Mumbai. Dyes were \\
used as received. Aniline and HCl were obtained from Merck \\
Specialities (P) Ltd., Mumbai. Ammonium persulphate was \\
obtained from Loba Chemie Pvt. Ltd., Mumbai. Copper(II) \\
chloride was obtained from E. Merck (India) Ltd., Mumbai. \\
Structures of dyes are shown in Fig. 1.
\end{tabular}






Fig. 1. Structures of dyes

Preparation of stock dye solution: Stock solution of each dye (naphthol blue black B, metanil yellow, acid blue 9 and amaranth) was prepared by dissolving $0.5 \mathrm{~g}$ of dye in distilled water and making it up to $100 \mathrm{~mL}$ in a standard flask.

Standardization of dye solution: Naphthol blue black B, metanil yellow, acid blue 9 and amaranth were standardized by measuring the optical densities of the various concentrations of the dye solution at $618,442,629$ and $522 \mathrm{~nm}$, respectively by using visible spectrophotometer (Chemiline).

Preparation of PANI-CuCl 2 : Copper chloride doped polyaniline was synthesized by chemical oxidation coupled with polymerization, where ammonium persulphate was used as an oxidant. Appropriate amount of ammonium persulphate dissolved in water was mixed with solution of aniline dissolved in $1.5 \mathrm{M} \mathrm{HCl}$ and then $\mathrm{CuCl}_{2}$ dissolved in water, where added into the solution mixture and stirred at $400 \mathrm{rpm}$ for $5 \mathrm{~h}$ at room temperature. A colour change from golden yellow through blue to dark green was observed. After the polymerization, the solution was filtered, washed and dried leading to $\mathrm{CuCl}_{2}$ doped PANI sample [15].

Adsorption experiment: $100 \mathrm{~mL}$ of dye solution of required concentration was taken in a $250 \mathrm{~mL}$ beaker which contains the required amount of PANI- $\mathrm{CuCl}_{2}$ composite. The solution was exposed to sunlight. At appropriate time interval $10 \mathrm{~mL}$ of aliquot was withdrawn, centrifuged and filtered. The filtrate was collected separately in a clear dry test tube and then the optical density of the clear supernatant dye solution was measured till the equilibrium was attained.

Variation of contact time: Effect of contact time was studied by taking $100 \mathrm{~mL}$ of dye solution with appropriate concentrations in a $250 \mathrm{~mL}$ beaker containing $0.03 \mathrm{~g}$ of $8 \%$ PANI-CuCl$l_{2}$.

Effect of initial dye concentration: Effect of initial dye concentration was observed by varying concentrations of dye in the range, naphthol blue black B (2.5 to12.5 mg/L), metanil yellow (13 to $25 \mathrm{mg} / \mathrm{L})$, acid blue $9(0.5$ to $4.5 \mathrm{mg} / \mathrm{L})$, amaranth ( 1.0 to $5.0 \mathrm{mg} / \mathrm{L}$ ) with $0.3 \mathrm{~g} / \mathrm{L}$ of $8 \%$ PANI-CuCl 2 .

Effect of dosage of adsorbent: To evaluate the percentage decolourization dependence on the dosage of adsorbent was studied by varying dosage of $8 \%$ PANI- $\mathrm{CuCl}_{2}$ from 0.1 to 0.7 $\mathrm{g} / \mathrm{L}$ with suitable concentration of dye.

Effect of temperature: The effect of temperature was studied at four different temperatures from 30 to $45^{\circ} \mathrm{C}$.
Effect of pH: The effect of $\mathrm{pH}$ on decolourization was studied at $\mathrm{pH} 4$ to 9 .

Effect of $\% \mathrm{CuCl}_{2}$ in PANI-CuCl $\mathbf{C u}_{2}$ : The influence of percentage of $\mathrm{CuCl}_{2}$ dopant in PANI-CuCl${ }_{2}$ composite was investigated by varying the percentage of $\mathrm{CuCl}_{2}$ from 4 to 16 $\%$ on decolourization.

Desorption studies: The dye adsorbed $8 \%$ PANI- $\mathrm{CuCl}_{2}$ was mixed with $100 \mathrm{~mL}$ of aqueous acid or base $(0.1,0.025 \mathrm{~N}$ $\mathrm{HCl}$ and $0.1,0.025 \mathrm{~N} \mathrm{NaOH})$ is subjected to agitation with exposure to solar light. The solution after appropriate time interval was centrifuged. The optical density of the centrifugate was measured.

Electrical conductivity: The effect of electrical conductivity of dye adsorbed PANI-CuCl $\mathrm{Cl}_{2}$ composites was measured by making a pellet of filtered, dried composite. The electrical conductivity was measured for $8 \%$ PANI-CuCl $\mathrm{Cl}_{2}$ composite.

\section{RESULTS AND DISCUSSION}

The adsorption studies of the following dyes have been investigated in the presence of sunlight between 10.00 A.M. and 03.00 P.M., naphthol blue black B (NBBB), metanil yellow (MY), acid blue 9 (AB 9) and amaranth (AM). The percentage of decolourization exhibited an increasing trend on the exposure to solar light increased and reached equilibrium (Fig. 2). In the absence of solar light the removal of dye percentage is negligible even after $24 \mathrm{~h}$.

Increase in dye concentration increases the time required to reach equilibrium and it was found that the percentage of removal was not varied considerably with change in initial

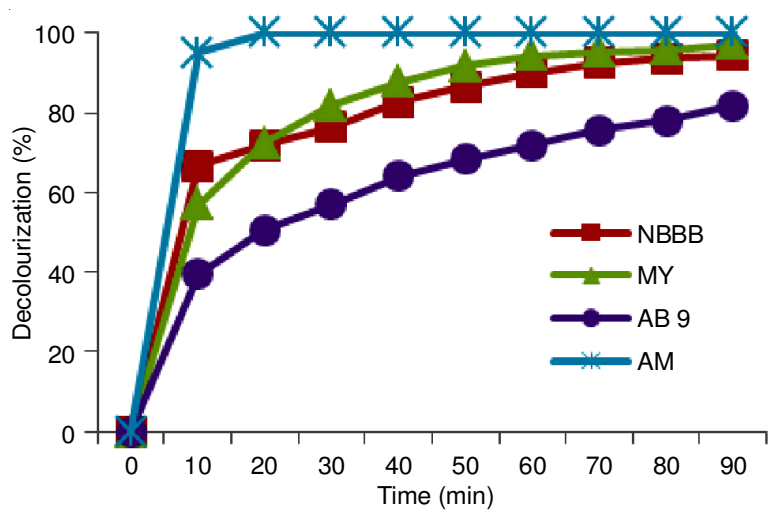

Fig. 2. Effect of contact time on $\%$ degradation 
dye concentration, blank run without adsorbent also carried out which shows negligible decolourization (Table-1).

The effect of variation in the quantity of $8 \% \mathrm{PANI}^{-\mathrm{CuCl}_{2}}$ composite (from 0.1 to $0.7 \mathrm{~g} / \mathrm{L}$ ) for each dye at $35^{\circ} \mathrm{C}$ was followed (Fig. 3). It was found that the percentage removal increased with increase in PANI- $\mathrm{CuCl}_{2}$ dosage and reached a limiting value. Results of effect of dosage were quite logical on the basis of increase in absorption site. The effect of percentage of $\mathrm{CuCl}_{2}$ in PANI-CuCl $\mathrm{Cl}_{2}$ composite on the rate of decolourization was investigated by varying the percentage of $\mathrm{CuCl}_{2}$ (from 4 to $16 \%$ ). The rate of decolourization increased considerably with increase of $\%$ of $\mathrm{CuCl}_{2}$ from 4 to $8 . \mathrm{Cu}^{2+}$ ions increase the photocatalytic activity upto certain concentrations [16]. The impact of percentage of $\mathrm{CuCl}_{2}$ on adsorption capacity was negligible beyond $8 \%$. The rate of decolourization of dyes by $8 \%$ PANI-CuCl${ }_{2}$ was found to be higher than PANI-ES (emeraldine salt). The influence of temperature on the rate of decolourization is negligible. This result indicates that the reaction is a photocatalyzed reaction. The $\mathrm{pH}$ of the medium plays a vital role on adsorption of dyes. The percentage of decolourization decreased with increase of $\mathrm{pH}$. The initial $\mathrm{pH}$ may affect the charge on the surface of the adsorbent, altering its capacity to adsorb dye molecule (Fig. 4).

The percentage of desorption increases with increase in concentration of $\mathrm{NaOH}$ but around $25 \%$ of initial concentration of dye only desorbed. The electrical conductivity of PANI-CuCl $\mathrm{Cl}_{2}$ composite after exposure to the dye solution is decreased considerably. This suggests that the dye adsorbed on the surface of the adsorbent gives a thin layer of doped materials which remove the chloride ion.

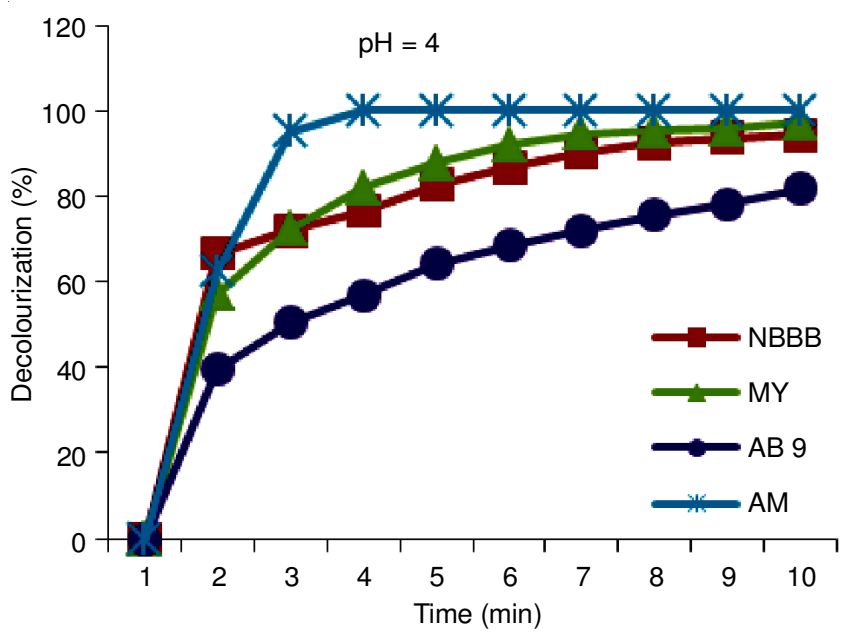

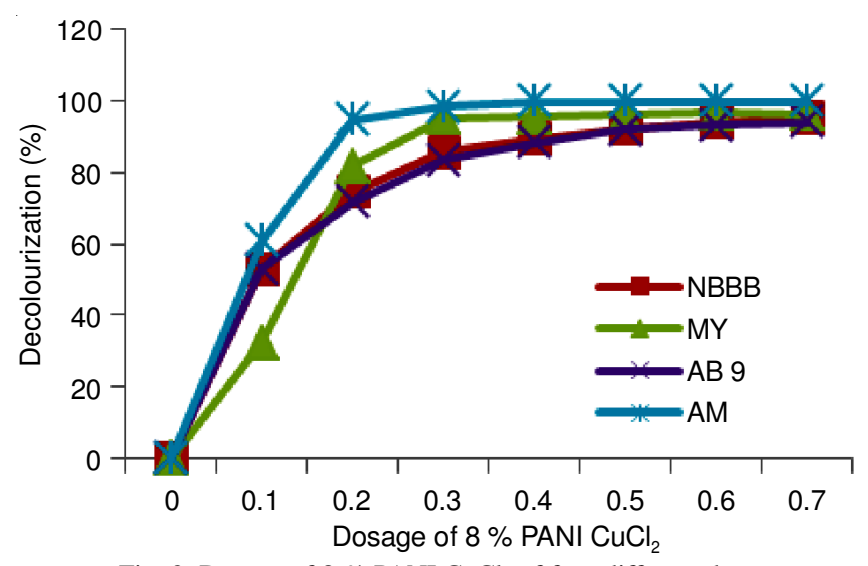

Fig. 3. Dosage of $8 \%$ PANI $\mathrm{CuCl}_{2}$ of four different dyes

Adsorption isotherm is usually the ratio between the quantity adsorbed and remaining in solution at fixed temperature. In the present study, the experimental data was fitted into Langmuir equation [17] and the plot of $\mathrm{C}_{\mathrm{e}} / \mathrm{q}_{\mathrm{e}}$ versus $\mathrm{q}_{\mathrm{e}}$ was found to be linear which indicates that the adsorption of above dyes over $8 \%$ PANI-CuCl 2 follows Langmuir isotherm (Fig. 5).

From Langmuir isotherm study calculated $\mathrm{R}_{\mathrm{L}}$ values proved that the adsorption of four dyes on PANI-CuCl $\mathrm{Cu}_{2}$ is a favourable process for the concentration range studied (Table2). $\mathrm{Q}_{0}$ and $\mathrm{B}$ are Langmuir constants related to adsorption capacity and rate of adsorption respectively.

Adsorption is a multilayer process, involving transport of solute particle from the aqueous phase to the surface of the solid adsorbent followed by diffusion into the interior pores.

Fig. 4. Effect of $\mathrm{pH}$ on dye removal efficiency at $\mathrm{pH} 4$ and 9

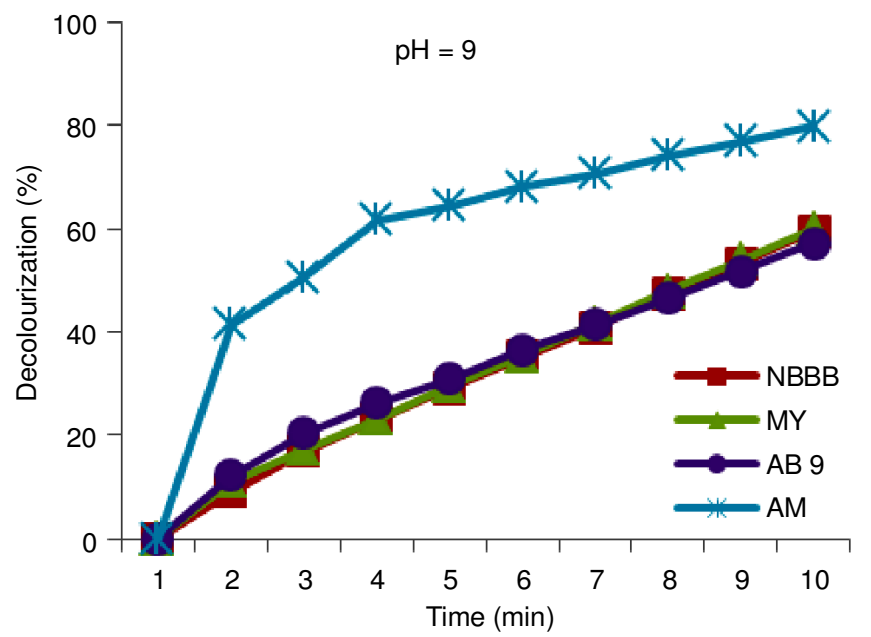

TABLE-1

EFFECT OF INITIAL DYE CONCENTRATION

\begin{tabular}{ccc|ccc|ccc|ccc}
\hline \multicolumn{2}{c|}{ Naphthol blue black B } & \multicolumn{3}{c|}{ Metanil yellow } & \multicolumn{3}{c|}{ Acid blue 9} & \multicolumn{3}{c}{ Amaranth } \\
\hline $\begin{array}{c}\text { Initial dye } \\
\text { conc. }(\mathrm{mg} / \mathrm{L})\end{array}$ & $\begin{array}{c}\text { Time } \\
(\mathrm{min})\end{array}$ & $\begin{array}{c}\text { Removal } \\
(\%)\end{array}$ & $\begin{array}{c}\text { Initial dye } \\
\text { conc. }(\mathrm{mg} / \mathrm{L})\end{array}$ & $\begin{array}{c}\text { Time } \\
(\mathrm{min})\end{array}$ & $\begin{array}{c}\text { Removal } \\
(\%)\end{array}$ & $\begin{array}{c}\text { Initial dye } \\
\text { conc. }(\mathrm{mg} / \mathrm{L})\end{array}$ & $\begin{array}{c}\text { Time } \\
(\mathrm{min})\end{array}$ & $\begin{array}{c}\text { Removal } \\
(\%)\end{array}$ & $\begin{array}{c}\text { Initial dye } \\
\text { conc. }(\mathrm{mg} / \mathrm{L})\end{array}$ & $\begin{array}{c}\text { Time } \\
(\mathrm{min})\end{array}$ & $\begin{array}{c}\text { Removal } \\
(\%)\end{array}$ \\
\hline 2.5 & 60 & 91.3 & 13 & 60 & 97.8 & 0.5 & 60 & 91.7 & 1 & 4 & 100 \\
5.0 & 70 & 94.9 & 16 & 70 & 98.3 & 1.5 & 70 & 96.1 & 2 & 6 & 100 \\
7.5 & 80 & 96.2 & 19 & 80 & 98.4 & 2.5 & 80 & 97.6 & 3 & 8 & 100 \\
10.0 & 90 & 97.4 & 22 & 90 & 98.5 & 3.5 & 90 & 98.2 & 4 & 10 & 97.9 \\
12.5 & 100 & 98.0 & 25 & 100 & 98.6 & 4.5 & 100 & 98.5 & 5 & 12 & 95.4 \\
\hline
\end{tabular}





Fig. 5. Langmuir isotherm plots for four dyes

\begin{tabular}{ccccc}
\multicolumn{5}{c}{ TABLE-2 } \\
LANGMUIR CONSTANTS \\
\hline Dye & B & $\mathrm{Q}_{0}$ & $\begin{array}{c}\text { Correlation } \\
\text { coefficient }(\mathrm{r})\end{array}$ & $\mathrm{R}_{\mathrm{L}}$ \\
\hline NBBB & 33.333 & 30.000 & 0.999 & 0.750 \\
MY & 13.636 & 73.333 & 0.999 & 0.880 \\
AB 9 & 31.250 & 06.400 & 0.999 & 0.762 \\
AM & 8.330 & 12.005 & 0.999 & 0.923 \\
\hline
\end{tabular}

The possibility of intra-particle diffusion is tested by plotting a graph between the amount of dye adsorbed and the time $t^{1 / 2}$ at different time intervals. The plot of $\mathrm{q}_{\mathrm{t}} v s . \mathrm{t}^{1 / 2}$ is linear indicates occurrence of intra-particle diffusion (Fig. 6). The plots of $t / q_{t}$ against $t$ were linear, showing that the reaction kinetics follows pseudo second order rate equation (Fig. 7).

Scanning electron microscopy is widely used to study the morphological features and surface characteristics of adsorbent

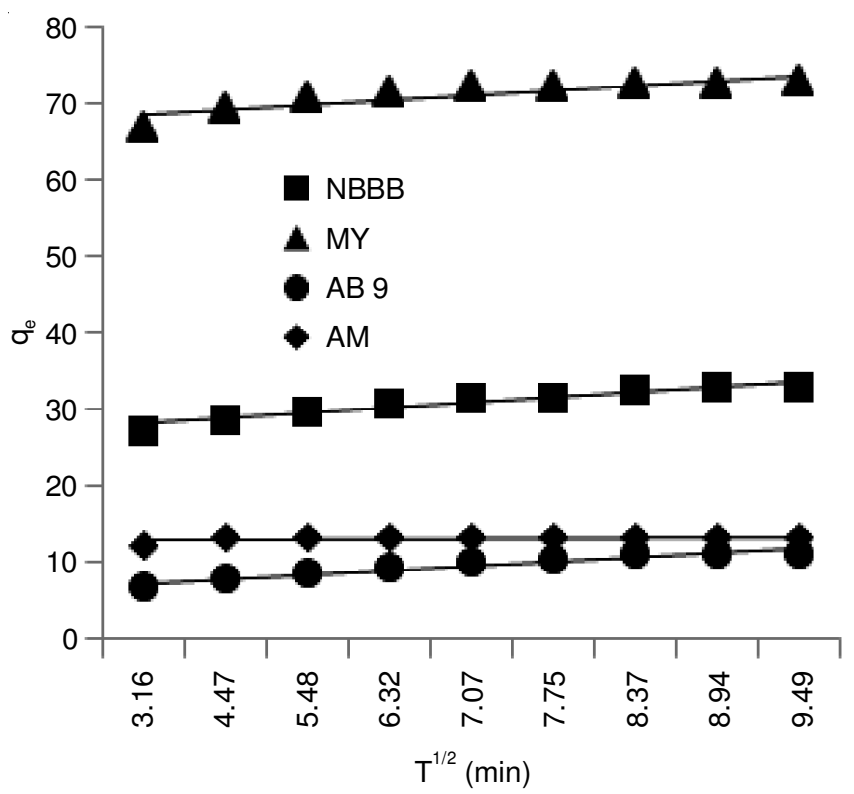

Fig. 6. Intraparticle diffusion model for four dyes

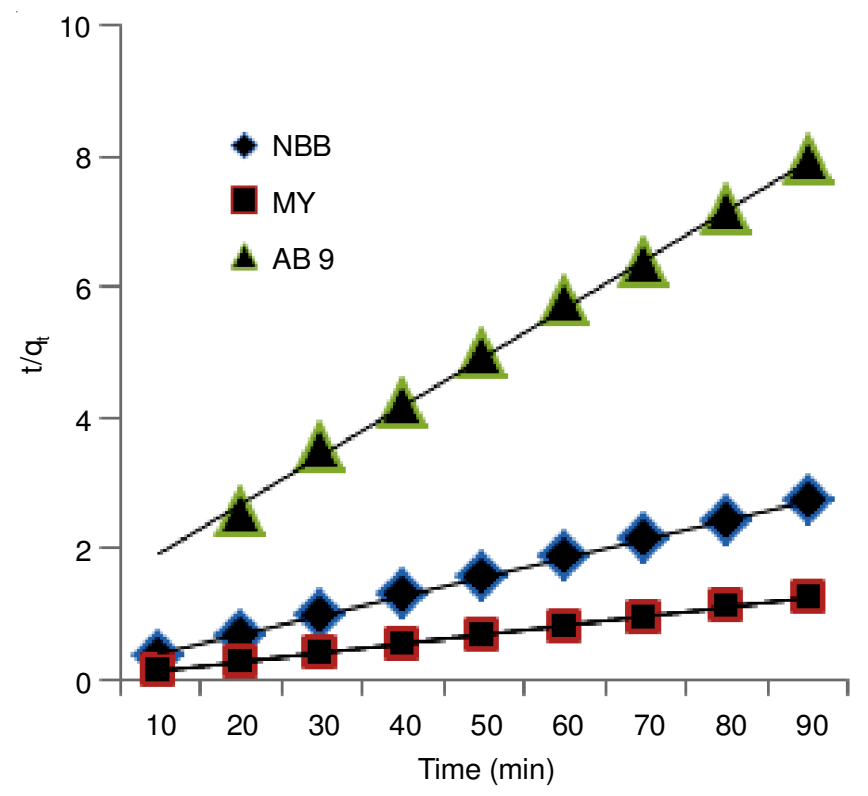

Fig. 7. Pseudo $2^{\text {nd }}$ order kinetics plot

materials. The SEM images of $\mathrm{CuCl}_{2}$ doped PANI (Fig. 8a) and dye adsorbed PANI-CuCl${ }_{2}$ composites [naphthol blue black B (Fig. 8b), metanil yellow (Fig. 8c), acid blue 9 (Fig. 8d) and amaranth (Fig. 8e)] shows different surface texture which reveals the adsorption of dyes on PANI- $\mathrm{CuCl}_{2}$ composite.

\section{Conclusion}

In this study copper chloride doped polyaniline composite was used for the effective removal of naphthol blue black B, metanil yellow, acid blue 9 and amaranth by adsorption process assisted by solar light. It is concluded that the process of adsorption under the experimental condition studied is a suitable method for the degradation of sulphonic acid dye and sulphonated azo dyes. 

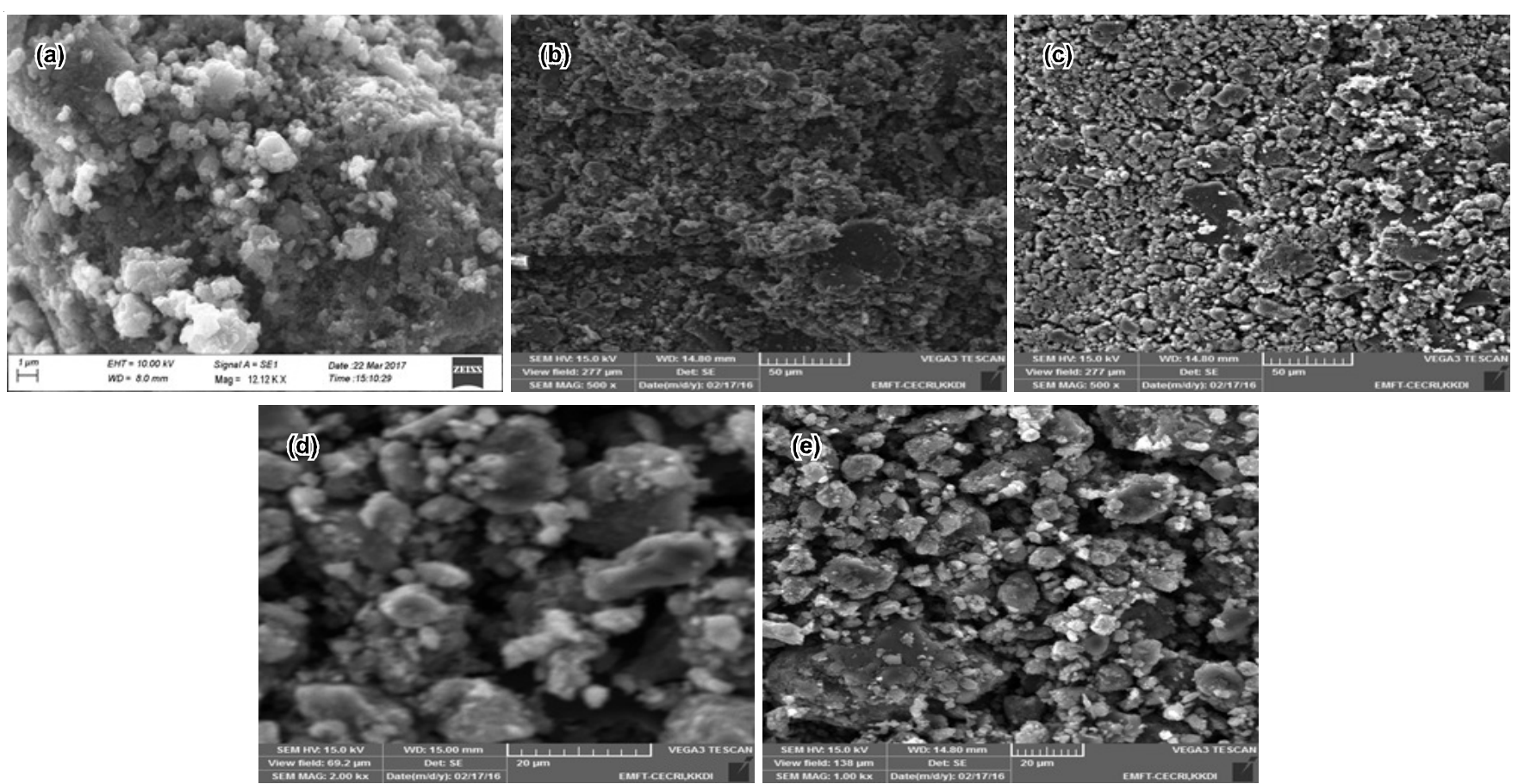

Fig. 8. SEM images of PANI-CuCl 2 , before adsorption (8a), after adsorption of naphthol blue black B (8b), metanil yellow ( $8 \mathrm{c})$, acid blue 9 (8d) and amaranth (8e)

\section{REFERENCES}

1. T. Basile, A. Petrella, M. Petrella, G. Boghetich, V. Petruzzelli, S. Colasuonno and D. Petruzzelli, Ind. Eng. Chem. Res., 50, 8389 (2011); https://doi.org/10.1021/ie101919v.

2. H. Ali, Water Air Soil Pollut., 213, 251 (2010); https://doi.org/10.1007/s11270-010-0382-4.

3. J.M.M. Orfao, A.I.M. Silva, J.C.V. Pereira, S.A. Barata, I.M. Fonseca, P.C.C. Faria and M.F.R. Pereira, J. Colloid. Interface Sci., 296, 480 (2006); https://doi.org/10.1016/j.jcis.2005.09.063.

4. Y. Peng, D. Fu, R. Liu, F. Zhang and X. Liang, Chemosphere, 71, 990 (2008); https://doi.org/10.1016/j.chemosphere.2007.10.065.

5. A. Azam and A. Hamid, J. Hazard. Mater., 133, 167 (2006); https://doi.org/10.1016/j.jhazmat.2005.10.005.

6. K.C. Chen, J.Y. Wu, C.C. Huang, Y.M. Liang and S.C.J. Hwang, J. Biotechnol., 101, 241 (2003); https://doi.org/10.1016/S0168-1656(02)00362-0.

7. S. Yang, P. Wang, X. Yang, L. Shan, W. Zhang, X. Shao and R. Niu, J. Hazard. Mater, 179, 552 (2010); https://doi.org/10.1016/j.jhazmat.2010.03.039.

8. V. Zope, M. Kulkarni and M. Chavan, J. Sci. Ind. Res. (India), 66, 411 (2007).
9. S.H.S. Chan, T. Yeong Wu, J.C. Juan and C.Y. Teh, J. Chem. Technol. Biotechnol., 86, 1130 (2011); https://doi.org/10.1002/jctb.2636.

10. D. Georgiou, P. Melidis, A. Aivasidis and K. Gimouhopoulos, Dyes Pigments, 52, 69 (2002); https://doi.org/10.1016/S0143-7208(01)00078-X.

11. R. Sivakumar, K. Ganesh and M. Karthikeyan, Int. J. Comp. Org. Trends, 8, 20 (2014);

https://doi.org/10.14445/22492593/IJCOT-V8P304.

12. J.R. Baseri, P.N. Palanisamy and P. Sivakumar, E-J. Chem., 9, 1266 (2012); https://doi.org/10.1155/2012/415234.

13. M.R. Patil and J. Shrivastava, J. Mater. Environ. Sci, 6, 11 (2015).

14. M.T.-L. Mihali, N. Pksu, A. Kellenberger and G. Lila, Int. J. Electrochem. Sci., 10, 7643 (2015).

15. D. Bingol, S. Veli, S. Zor and U. Ozdemir, Synth. Met., 162, 1566 (2012); https://doi.org/10.1016/j.synthmet.2012.07.011.

16. N. Yamamoto, T. Isobe, S. Matsushita and A. Nakajima, J. Ceram. Soc. Jpn., 120, 483 (2012);

https://doi.org/10.2109/jcersj2.120.483.

17. I. Langmuir, J. Am. Chem. Soc., 40, 1361 (1918); https://doi.org/10.1021/ja02242a004. 